\title{
A gênese da ciência política brasileira*
}

\author{
Fábio Cardoso Keinert e Dimitri Pinheiro Silva
}

A análise do processo de autonomização disciplinar da ciência política no Brasil remete a um exame mais circunscrito referente à experiência de um grupo geracional formado em Belo Horizonte e no Rio de Janeiro. A fisionomia que o perfil da disciplina assumiu a partir de fins da década de 1960 é tributária das iniciativas dessa geração, especialmente marcada pelos influxos internacionais estimulados pela Fundação Ford. No âmbito da sociabilidade vivida pelo grupo, um cânone disciplinar era construído articulando as novidades trazidas dos Estados Unidos com referências ligadas aos ensaios de interpretação sobre a história política do Brasil.

Trata-se de uma perspectiva que se constitui mediante uma relação bastante estreita com a conjuntura política inaugurada pelo golpe militar de 1964. É possível afirmar que a reação do grupo de cientistas políticos aos problemas postos pela conjuntura adversa se expressava em duas linhas básicas de reflexão: de um lado, a de compreender as razões ligadas à emergência do autoritarismo e, de outro, a de delinear uma plataforma política que pudesse orientar a recomposição do regime democrático no Brasil. A realização de estudos direcionados ao sistema político retirava fôlego da expectativa de intervenção ligada ao horizonte das reformas previstas para o momento de transição. Num contexto em que a intelectualidade brasileira estava especialmente sensível à dimensão política, a nova modalidade disciplinar conquistaria legitimidade por sua potencial con-
${ }^{*}$ Esse artigo apresenta resultados de nossas pesquisas de mestrado e doutoramento, realizadas com auxílio da Fapesp. Agradecemos em especial aos professores Sergio Miceli e Luiz Carlos Jackson pelas leituras e sugestôes, que nem sempre, porém, pudemos acolher de maneira integral. 
1.O referido texto teve duas versōes preliminares. Ambas foram publicadas na revista Dados. Cf. Santos, 1967, 1970. tribuição prática às diversas ações voltadas à redemocratização do país, tais como as iniciativas do Movimento Democrático Brasileiro (MDB) - então a única legenda de oposição ao regime -, o movimento pelo restabelecimento das eleiçóes diretas e o esforço em prol de uma assembléia nacional constituinte.

A possibilidade de construir uma modalidade própria de intervenção política combinava-se à invocação de novos parâmetros de cientificidade, vistos como traço distintivo de um perfil de trabalho que se apoiava num ideal renovado de profissionalismo. A reivindicação do caráter "moderno" da iniciativa, um dos eixos principais da estratégia de legitimação do grupo, implicava a recusa das referências acadêmicas da geração imediatamente anterior, representada, sobretudo, pela chamada "escola paulista de sociologia”, cuja hegemonia no cenário brasileiro das ciências sociais declinaria justamente em fins dos anos de 1960, por ocasião das cassações impostas pelo regime militar.

No entanto, a ideia de inovação acadêmica não excluía a reivindicação de uma tradição, no âmbito da história das ideias, que vinculasse a novidade proposta às referências mais antigas de gerações da intelectualidade brasileira às voltas com o problema da formação do Brasil. A ruptura que se pretendia introduzir no campo das ciências sociais exigiria, ao mesmo tempo, o apelo a uma tradição, cujo suposto de antiguidade se constituía como aporte simbólico de legitimidade.

Esta questão pode ser percebida especialmente no texto "Paradigma e história: a ordem burguesa na imaginação social brasileira”, de Wanderley Guilherme dos Santos, cuja primeira versão, de 1967, é indicativa do momento em que o debate se inicia ${ }^{1}$. Nesse artigo, Santos constrói uma representação sobre as origens da ciência política, localizando no chamado pensamento autoritário dos anos de 1920 e de 1930 - exemplificado em autores como Oliveira Vianna, Alberto Torres e Azevedo Amaral -, o manancial de uma tradição de estudos políticos que teria redundado na versão "moderna" da disciplina.

As filiações são construídas a partir de uma visão da história intelectual em que o passado das ideias vai sendo arrumado segundo a lógica da constituição imaginária de uma linhagem. A tradição que se forjava implicava a elaboração de uma nova periodização da história das ciências sociais que valorizasse justamente a contribuição dos ensaios do início do século, o que marcava a exigência de se relativizar a ideia de que a estrutura universitária é a principal fonte de legitimidade intelectual. 
Ao defender o primado das ideias no desenvolvimento das ciências sociais, Santos recusava o "mito de fundação" difundido pela sociologia paulista, que tomava a criação da Escola Livre de Sociologia e Política (1933) e da Faculdade de Filosofia, Ciências e Letras da Universidade de São Paulo (1934) como ponto de partida para o desenvolvimento efetivo das ciências sociais no Brasil. Sua crítica ao "paradigma institucional" - endereçada especialmente a Florestan Fernandes - questionava o caráter arbitrário da perspectiva que representava a evolução dessas disciplinas em função da passagem de um estágio pré-científico para o científico, cujo ponto de inflexão seria exatamente o advento das instituições acadêmicas. Desse modo, a objeção de Santos revelava a parcialidade de um ponto de vista que seria mais favorável à versão que enfatiza o êxito do processo de construção do aparato institucional da USP. Assim, a experiência do grupo adquire significados importantes quando situada no âmbito da clivagem regional que opôs a cidade de São Paulo à do Rio de Janeiro.

Este artigo está organizado em duas partes. Na primeira, procura esclarecer as circunstâncias ligadas à formação dos membros do grupo geracional com o intuito de explicitar os laços existentes entre as suas disposições intelectuais e a adesão a certos padrões de carreira e de aspiração. Em seguida, tenciona iluminar a dimensão simbólica do seu processo de afirmação, focalizando as representações criadas em torno de uma ideia de filiação que se constitui a partir de balanços sobre a história do pensamento social no Brasil.

A adoção da nomenclatura "Ciência Política" para designar o campo disciplinar é um dos sinais mais expressivos da lógica que redefiniu os traços identitários de uma área de estudos, cuja designação mais habitual era dada até então pelo termo "Política". O sintagma que se cria com a incorporação do termo "Ciência" revela um dos componentes centrais da afirmação de certo perfil intelectual construído em consonância com os novos parâmetros de cientificidade, formulados especialmente no âmbito das ciências sociais praticadas nos Estados Unidos. A sofisticação das técnicas quantitativas de pesquisa aparecia como símbolo maior de um empreendimento cujo sentido de inovação se apoiava num diagnóstico acerca do que seriam as fragilidades metodológicas da ciência social praticada no Brasil até a primeira metade da década de 1960, que valeria tanto para os sociólogos da 
2. Uma análise mais abrangente da ação das agências filantrópicas nos marcos das diretrizes da política externa norte-americana para os países da América Latina - especialmente Argentina, Brasil, Chile e México - pode ser encontrada em Yves Dezalay e Bryant Garth (2002).
USP como para os cientistas sociais reunidos no Instituto Superior de Estudos Brasileiros (Iseb), no Rio de Janeiro.

Ao mesmo tempo em que rechaçava as principais referências nacionais da sociologia da época, a vanguarda científica abria-se aos influxos acadêmicos das ciências sociais norte-americanas. Tais influxos devem ser tomados como parte de um quadro mais amplo de relações de trocas acadêmicas entre nações, em que a atuação da Fundação Ford assumiria papel decisivo. O esforço de exportação de um modelo de organização do trabalho intelectual adquiria sentido no âmbito de um projeto mais abrangente de hegemonia cultural dos Estados Unidos para a América Latina, cujas motivações iniciais se associavam às tensões ligadas ao contexto da Guerra Fria, agravadas ainda mais após a eclosão da Revolução Cubana em 1959. Espécie de ação profilática contra a disseminação da suposta influência do comunismo na regiāo, a atuação da Fundação Ford punha em prática as diretrizes definidas pela política externa do governo norte-americano, que adquiriu feição com o lançamento da campanha "Aliança para o Progresso", elaborada sob a presidência de John Kennedy. O ideário desenvolvimentista constituía o eixo articulador dessa política de "assistência” às chamadas nações subdesenvolvidas ${ }^{2}$.

Diferentemente da estratégia adotada para regiōes como África, Ásia e Oriente Médio, que envolveu prioritariamente auxílio a órgãos governamentais, a orientação seguida pelas primeiras “missōes” da Fundação Ford na América Latina optou pelo investimento em instituições acadêmicas. Inicialmente restrito ao universo das áreas de economia e de administração, esse investimento passou a contemplar outras especialidades científicas conforme os diagnósticos acerca do desenvolvimento foram concedendo maior ênfase aos fatores extraeconômicos, tais como aspectos institucionais e culturais. No âmbito dessa ampliação do escopo das políticas de apoio, as ciências sociais adquirem prioridade, uma vez que figuravam como instrumentos de uma espécie de "engenharia social" dos processos de modernização (Miceli, 1993, p. 43).

Uma vez que as iniciativas de apoio da Fundação Ford apontavam para uma definição aplicada de conhecimento social, a ciência política viria a assumir uma posição estratégica em função de seu potencial em pautar a elaboração de políticas públicas. Trata-se da viabilização de um perfil disciplinar especializado que se ligaria a um gênero de pesquisas orientado pela proximidade à agenda política nacional e cujos esforços seriam canalizados para a análise das bases institucionais do regime liberal-democrático. A de- 
manda por cientificidade implicaria a assimilação de métodos e técnicas quantitativos, como via privilegiada de acesso à compreensão da dinâmica do sistema político. A amplitude da valorização do aparato metodológico pode ser dimensionada quando se tem em vista a centralidade que o survey adquiriria no âmbito das pesquisas políticas.

Em 1964, Peter Bell, então representante da Fundação Ford no Brasil, encontrou na cidade de Belo Horizonte um núcleo de cientistas sociais cujas disposições pareciam se ajustar de modo bastante favorável ao perfil intelectual que a agência pretendia estimular. A experiência de socialização acadêmica no âmbito da Faculdade de Administração e Ciências Econômicas (Face) - posteriormente incorporada à Universidade Federal de Minas Gerais (UFMG) -, onde o curso de Sociologia e Política havia sido implantado em 1953, moldou um tipo de visão de mundo que se mostraria suscetível aos reclamos por uma ciência política mais especializada e aplicada.

É possível afirmar que alguns dos aspectos formadores dessas disposições intelectuais já estavam explícitos no projeto de criação da Face, em 1941. Viabilizada por uma rede envolvendo empresários, técnicos do alto escalão governamental e políticos de envergadura nacional, a faculdade integrava os esforços despendidos no sentido de superar a situação de defasagem da economia mineira, meta que colocava na ordem do dia a preocupação com a formação de profissionais capacitados para lidar com as tarefas de gestão pública e privada (Arruda, 2001, p. 297). A inclusão das ciências sociais numa faculdade de administração e economia representaria uma inovação significativa em face do formato institucional mais difundido de inserção daquelas disciplinas nas faculdades de filosofia, conforme atestam os casos paulista e fluminense. A vocação intervencionista da faculdade incide diretamente na organização do Curso de Sociologia e Política, direcionandoo para a formação de quadros para a burocracia pública mineira.

Sob o mote da capacitação de pessoal técnico para a atuação na esfera governamental, as ciências sociais não poderiam deixar de sofrer a influência decisiva das áreas do direito, da economia e da administração, que compunham a estrutura curricular do curso, conferindo-lhe um perfil substantivamente diverso, por exemplo, da formação oferecida pela Faculdade de Filosofia, Ciências e Letras da USP, mais próximo do modelo humanista clássico ${ }^{3}$. Parece plausível afirmar que a interação com as referidas disciplinas está na origem do especial interesse dos cientistas políticos mineiros por aspectos político-institucionais da vida social, a partir dos quais se montaria um leque temático de pesquisas (Miceli, 2001, p. 25).
3. Sobre a idealização da FFCL-USP, consultar Limongi (2001). 
4. Entrevista concedida aos autores. Além de tal experiência comum de socialização acadêmica, parece possível associar a referida coesão do grupo às afinidades derivadas de uma origem social comum. Como bem demonstrou o levantamento realizado por Letícia Canedo, os alunos recrutados pelo sistema de bolsas da Face provinham, sobretudo, de famílias modestas, sem vinculaçōes com os seletos círculos da oligarquia política mineira, mas, ainda assim, em condições de arcar com um pesado investimento em capital escolar. Não por acaso, a maior parte deles constituía a primeira geração, no âmbito de suas respectivas famílias, alçada ao nível superior de ensino, justamente numa faculdade que estava fora do circuito percorrido pelos herdeiros da elite dirigente do Estado (Canedo, 2009, pp. 9-10). Ver também Canedo (2003, 2004).
Para contornar o problema da ausência de um corpo de professores não especializado em ciências sociais, os mentores da Face introduziram inovações organizacionais com vistas a dotar a própria faculdade das condições necessárias à capacitação e à reprodução do seu quadro docente. A medida que mais chama atenção diz respeito à implantação de um sistema hierarquizado de bolsas de estudos dirigidas ao corpo discente, que exigia dedicação integral, auxílio às atividades didáticas e apresentação de monografias ao final do ano (Arruda, 2001, p. 304). O sistema de bolsas engendrou a constituição de dois segmentos entre os alunos, que se distinguiam justamente pelo tipo de envolvimento que mantinham com a faculdade: de um lado, os chamados alunos "regulares" e, de outro, a "elite". No primeiro, estavam aqueles que, uma vez diplomados, se lançariam a ocupar os postos abertos no mercado profissional. Já no segundo, figuravam os alunos bolsistas, potenciais candidatos a integrar o quadro permanente da instituição.

O sistema de bolsas e a dedicação integral vivenciados no período de graduação informam muito sobre o universo mental em meio ao qual o grupo geracional se formou. Tal regime de estudos forneceu as condições tanto para a consolidação de uma concepção profissionalizada de vida acadêmica, como para a modelagem de um tipo de ambição na carreira, nas quais as noçôes de "elite" e de "excelência" seriam constantemente evocadas. $\mathrm{O}$ anseio de se alçar aos postos de poder institucional no campo das ciências sociais também dá mostra das aspirações que moveram alguns desses percursos, conforme se pode notar pelo exemplo de Olavo Brasil de Lima Jr., um dos idealizadores da Associação Nacional de Pesquisa e Pós-Graduação em Ciências Sociais (Anpocs), fundada em 1977.

Além disso, o sistema de bolsas desempenharia também um papel importante na composição de um grupo bastante coeso no que se refere ao padrão de carreira. Em depoimento, Bolívar Lamounier ressalta a dimensão afetiva da convivência diária entre os bolsistas da Face como indispensável à criação de um "espírito de corpo muito forte", uma das fontes, segundo ele, das semelhanças que marcam os percursos dos egressos da instituição mineira ${ }^{4}$.

O modelo estabelecido em Belo Horizonte, no entanto, não chegou a ser plenamente autorreprodutível. Inicialmente, a ausência de um currículo centrado em disciplinas atinentes às ciências sociais obrigaria os diplomados pelo Curso de Sociologia e Política a complementar sua formação em outros centros intelectuais, como a Faculdade Latino-Americana de Ciências Sociais (Flacso), no Chile, e as universidades norte-americanas. 
Posteriormente, a limitação no horizonte de oportunidades em Minas Gerais, onde não havia centros ou núcleos de pesquisa em condições de absorver esses profissionais acadêmicos, também estimulou a imigração intelectual, que encontraria no Rio de Janeiro seu paradeiro preferencial (Arruda, 2001, pp. 320-321).

Os cursos de especialização, então, recém-abertos na Flacso, apareciam, no início da década de 1960, como possibilidade privilegiada de realizar um "treinamento" acadêmico mais especificamente ligado à dimensão empírica da investigação social. A experiência vivida por Simon Schwartzman, Fábio Wanderley Reis e Antônio Octávio Cintra, entre 1962 e 1963, teria sido o primeiro impulso de um processo de conversão que se completaria com as viagens aos Estados Unidos, alguns anos depois. A novidade trazida de Santiago repercutira imediatamente em Belo Horizonte, já que os jovens pósgraduados seriam admitidos como parte do quadro docente da Face. José Murilo de Carvalho, ao relembrar sua experiência como ex-aluno dos três professores - apesar da mínima diferença de idade -, assinala a inflexão que o curso sofreria: "E aí sim, entrou um outro estilo de pensamento, uma outra orientação: entrou a ciência política americana, via Flacso"s.

A estadia em Santiago desempenhou um papel importante no processo de afirmação do grupo, que passou a associar sua autoimagem ao novo repertório metodológico assimilado. Não por acaso, a familiaridade no trato com as técnicas quantitativas seria empregada como peça-chave da estratégia de desqualificação dos grupos acadêmicos rivais, sobretudo no caso daqueles radicados na USP. O artigo de Fábio Wanderley Reis, "A propósito de ciência e dialética", de 1966, é especialmente revelador dessa tomada de posição. Aproveitando o ensejo de uma discussão com José Arthur Giannotti acerca do método dialético, o cientista político mineiro critica o que seria, do seu ponto de vista, uma tendência típica verificada em alguns autores paulistas inspirados no marxismo - tais como Fernando Henrique Cardoso, Octávio Ianni, Francisco Weffort e o próprio Giannotti -, de priorizar conceitos em detrimento do trabalho sistemático com o material empírico. A crítica desferida por Reis se faz no registro da defesa do que seria um "compromisso mais sério com padrôes que orientam o trabalho dos estudiosos dos fenômenos sociais num sentido em que tal trabalho possa ser fonte de aquisição de conhecimentos e não reiteração indefinida de princípios gerais" (Reis, 1966, p. 303).

Além do incentivo financeiro concedido à criação de novas instituições, conforme indica o caso pioneiro da doação destinada ao Departamento de
5. Entrevista concedida a Oliveira, Ferreira e Castro (1998). 
6. Características similares são verificáveis nas trajetórias de economistas que foram formados pela Face e também contaram com o financiamento da Fundação Ford para realização de seus estudos nos Estados Unidos: Edmar Lisboa Bacha e Cláudio Moura e Castro. O primeiro integrou as equipes responsáveis pela elaboração dos planos Cruzado - durante a presidência da República de José Sarney (19851990) - e Real - durante a presidência de Itamar Franco (19921995) -, e também dirigiu o Banco Nacional de Desenvolvimento Econômico e Social (BNDES) - sob a presidência de Fernando Henrique Cardoso (1995-2003). O segundo foi diretor geral da Coordenação de Aperfeiçoamento de Pessoal de Nível Superior (Capes), entre 1979 e 1982 , e secretário executivo do Conselho Nacional para Recursos Humanos (CNRH) - órgão de assessoria do Ministério do Planejamento -, de 1982 a 1985.

7.A possibilidade de se estabelecer no Rio de Janeiro foi considerada,
Ciência Política da UFMG, de 1965, a Fundação Ford mantinha como um dos eixos de suas operações o estímulo a viagens de estudos ao exterior, sendo as universidades norte-americanas o destino invariável de cientistas políticos mineiros e cariocas. A concessão das bolsas propiciava a incorporação de um repertório a um só tempo técnico e doutrinário por parte de pesquisadores que viriam a compor as novas elites científicas e de assessoria de governo. Condizente com o ideário desenvolvimentista, a intenção era formar acadêmicos capacitados à elaboração de projetos para a "modernização" do país, o que incluía a exigência de reformar o próprio sistema universitário-científico.

A experiência nos Estados Unidos, transcorrida entre os anos de 1960 e de 1970, atualizava uma das principais características do curso da Face: a valorização do profissional de "excelência", cujo horizonte de carreira apontaria para a possibilidade de atingir postos de comando na estrutura governamental. Os casos de Bolívar Lamounier e de Simon Schwartzman podem ser mobilizados a fim de que se ilustre perfis de trajetórias percorridas na fronteira entre a atividade acadêmica, a atividade política e de assessoria técnica. Em 1985, Lamounier foi chamado para integrar a Comissão Afonso Arinos, que elaborou o anteprojeto de constituição para o Brasil. A referida data marcou também o seu progressivo afastamento do mundo universitário, chegando até a se candidatar a deputado, nas eleições de 1986. Schwartzman, por sua vez, engajou-se, a partir da segunda metade dos anos de 1970, em pesquisas sobre o ensino superior, que se associavam ao objetivo de conceber projetos de políticas públicas para as áreas de educação e de ciência e tecnologia. Neste âmbito de atuação, ocupou o cargo de assessor da Financiadora de Estudos e Projetos (Finep), entre 1976 e 1979, assim como o de presidente do Instituto Brasileiro de Geografia e Estatística (IBGE), de 1994 a $1998^{6}$.

A criação do programa de pós-graduação em ciência política do Instituto Universitário de Pesquisas do Rio de Janeiro (Iuperj), em 1969, - iniciativa mais emblemática da institucionalização do novo perfil disciplinar resultou da conformação de uma aliança entre cientistas políticos de Belo Horizonte e do Rio de Janeiro ${ }^{7}$. Não há dúvida de que as "viagens iniciáticas" financiadas pela Fundação Ford foram indispensáveis à consecução dessa aliança, na medida em que conformaram as bases de uma mesma mentalidade profissional.

Não obstante, outro aspecto merece ser destacado com o intuito de iluminar as possíveis razôes das afinidades entre as disposições intelectuais de 
mineiros e cariocas. Trata-se da possibilidade de tomar as trajetórias em função de seu enraizamento em contextos intelectuais e institucionais, com características passíveis de serem aproximadas. Apesar de suas especificidades, as experiências do desenvolvimento das ciências sociais no Rio de Janeiro e em Belo Horizonte desenrolaram-se de forma muito próxima à esfera política. Conforme a sugestão de Maria Cecília Forjaz, a inclinação para a política dos mineiros encontraria "eco na tradição intervencionista e militante das ciências sociais no Rio de Janeiro, imensamente marcada pela experiência isebiana” (Forjaz, 1997, p. 11).

É preciso reforçar que as semelhanças se revelam pelo grau de proximidade da atividade acadêmica em relação à prática de intervenção política. No entanto, as similitudes não devem ser exageradas, sobretudo quando os matizes ideológicos implicados nas duas experiências são considerados. Tal ressalva se faz especialmente necessária em função do caráter peculiar da trajetória de Wanderley Guilherme dos Santos, que se distancia dos traços que marcam a formação inicial do grupo de Minas Gerais.

Natural do Rio de Janeiro, Santos graduou-se em filosofia pela antiga Universidade do Brasil em 1958, época em que passou a integrar os quadros


ideológica sustentada pelo Instituto, o cientista político não passaria incólume sob o clima intelectual do início da década de 1960, centrado no debate sobre o desenvolvimento e que não excluía a influência marxista ${ }^{9}$. O período do doutoramento realizado na Universidade de Stanford, que se encerraria em 1969 com a defesa da tese Impass and crisis in Brazilian politics, foi o ponto de virada de sua trajetória em direção ao novo mainstream da ciência política. A orientação anterior - fortemente impregnada pelo marxismo foi descartada, dando lugar à recusa radical do que era, segundo seu diagnóstico, uma presença excessiva do paradigma marxista nas ciências sociais praticadas durante os anos de $1970^{10}$.

$\mathrm{O}$ argumento da tese é especialmente revelador das apostas teóricas que que sustentavam a afirmação dos novos paradigmas da disciplina. $\mathrm{O}$ postulado da autonomia relativa do sistema político servia como justificativa à introdução de um repertório específico de técnicas de análise que superasse a tendência então dominante de interpretar a vida política como subproduto das constrições ligadas à estrutura socioeconômica. Seguindo a trilha desse raciocínio, Santos propõe uma interpretação bastante sui generis para o golpe de 1964, destacando causas ligadas à dinâmica interna do sistema representativo. A ruptura autoritária seria vista, assim, como resultante de por alguns, como mais favorável à construção de carreiras num centro com maior visibilidade do ponto de vista acadêmico e político. Trata-se dos casos de Bolívar Lamounier, Simon Schwartzman, Amaury de Souza, Edmundo Campos Coelho, Olavo Brasil de Lima Jr., Renato Boschi, José Murilo de Carvalho e Elisa Reis.

8. Sobre o perfil ideológico do Iseb, ver Toledo (1997).

9. Em artigo de 1963 , Santos recorre aos pressupostos da tradição marxista para fundamentar seu ajuste de contas com a "ideologia do desenvolvimento" tal como formulada nos quadros do Iseb. Para uma análise mais detalhada do significado dessa obra no conjunto da produção isebiana, ver Toledo (1997).

10. Sobre sua crítica à influência negativa do marxismo para as ciências sociais da América Latina, ver Santos (1980). 
uma crise institucional de "paralisia decisória", que teria marcado o mandato de João Goulart.

Santos desempenhou um papel destacado tanto na criação do Iuperj, em 1964, como do programa de pós-graduação aberto pela instituição em 1969, viabilizado pelo primeiro convênio com a Fundação Ford e sob o empuxo da reforma universitária. A centralidade de sua atuação revela-se de modo especialmente significativo no exame de alguns textos de caráter programático, nos quais procura definir os cânones da disciplina ainda em vias de se constituir e se consolidar no país. Indicaremos, a seguir, o eco que as representações do cientista político carioca encontrou nas formulações de Bolívar Lamounier, outra figura de proa na condução do processo de afirmação do campo disciplinar. A despeito das discordâncias entre eles, é patente a confluência dos esforços de ambos visando construir uma tradição para a perspectiva de estudos políticos à qual haviam aderido.

As representações que se criaram em torno da ideia de filiações intelectuais revelam o caráter multidimensional que marca o processo de afirmação do grupo. A partir desse ângulo de análise, constata-se que o discurso de ruptura não excluiu a defesa da noção contrária, isto é, uma ideia de continuidade que seria expressão dos elos que atariam a nova ciência política ao pensamento social produzido no Brasil no início do século XX. Na medida em que foi se estabelecendo, a vanguarda científica passou a se legitimar por meio do valor ligado a uma tradição construída em função da importância que o lastro simbólico de uma linhagem intelectual poderia oferecer. Assim, a tradição era forjada por meio de um balanço da história das ideias sociais e políticas, no Brasil, em que autores seriam destacados em maior ou menor grau, conforme a lógica que organizava a montagem da filiação.

Esse balanço sobre a produção do pensamento político-social fez-se paralelamente a uma avaliação da própria história brasileira, organizando uma versão sintonizada com as demandas postas pelo cenário político do presente. É nesse registro, por exemplo, que Bolívar Lamounier rejeitou as perspectivas historiográficas excessivamente "pessimistas" sobre a sociedade brasileira, justamente no momento em que a transição política em curso exigia, segundo ele, uma disposição favorável no sentido de viabilizar o sistema democrático-liberal. $\mathrm{O}$ interesse pela história do país pode ser interpretado em função da dinâmica própria ao mundo intelectual brasileiro, em que a 
formação das elites de pensamento estava ligada, em geral, ao exercício de construir representações sobre a nação. Em outros termos, as disputas intelectuais podem ser lidas na chave de um conflito por certo ideal de Brasil, o que, amiúde, conduziu os intelectuais à construção de um projeto político para a nação.

Wanderley Guilherme dos Santos, em seu artigo de 1975, localiza entre os anos de 1920 e 1930 uma inflexão no âmbito da produção do pensamento político-social, representada como marco inaugural de uma tradição que desembocaria na armação dos principais problemas da ciência política contemporânea. Para ele, tratava-se do nascimento de uma linhagem que destacava o tema crucial da disciplina: as relações entre a formação histórica do Brasil e sua estrutura política. Os autores daquele período definiram "solidamente o repertório de problemas que, sob roupagens linguísticas as mais variadas, se vem transmitindo de geração em geração, até hoje" (Santos, 1978, p. 39).

A ideia de continuidade, sugerida nesta passagem, é enfatizada no mesmo registro por Bolívar Lamounier, no trecho a seguir:

Essa tradição ou "estoque" anterior de pensamento político tem, a meu ver, uma importância decisiva para se compreender as características adquiridas pela ciência política que vai aos poucos se institucionalizando. Não só existe uma notável continuidade como, sobretudo, parece-me possível afirmar que o prestígio dessa tradição legitimou (e, talvez, exerceu certo efeito limitativo e canalizador sobre) o desenvolvimento da ciência política, a partir de 1945 (1982, p. 409).

Esse balanço sobre a implantação da disciplina, escrito em 1981, retoma um elogio que o próprio autor havia feito aos autores dos anos de 1920 e de 1930, em outro texto: "Formação de um pensamento político autoritário na primeira república: uma interpretação" (1977) ${ }^{11}$. A despeito das diferenças entre as perspectivas, os chamados críticos do modelo constitucional de 1891, como Alberto Torres, Oliveira Vianna, Azevedo Amaral e Francisco Campos, são citados por Lamounier em função do aspecto que os aproximaria, relativo à defesa do fortalecimento do poder público central. Segundo o autor:

A transformação do pensamento político no período considerado deve ser entendida basicamente como a formação de um sistema ideológico orientado no sentido de conceituar e legitimar a autoridade do Estado como princípio tutelar da sociedade (Lamounier, 1977, p. 356).
11.Este artigo publicado em 1977 é versão reduzida da tese de doutorado de Bolívar Lamounier, defendida em 1974: Ideology and authoritarian regimes: theoretical perspectives and a study of the Brazilian case. 
12. Santos toma como referência especialmente dois textos de Florestan Fernandes escritos, respectivamente, em 1957 e 1958: "Desenvolvimento históricosocial da sociologia no Brasil" e "O padrão de trabalho científico dos sociólogos brasileiros" (Fernandes, 1977).

13. Não parece demais lembrar que o esquema criticado pelos pioneiros da ciência política fora uma componente central da estratégia de legitimação acadêmica da sociologia que Florestan Fernandes havia levado a cabo na conjuntura intelectual imediatamente anterior. A tomada de posição do sociólogo paulista ligava-se à tarefa de afirmar certo padrão de trabalho científico, a importância da pesquisa empírica e da explicação sociológica em contraposição ao perfil intelectual associado ao autodidatismo e ao bacharelismo, características que eram, em bloco, associadas à tradição do pensamento social que se constituiu sem o suporte das novas instituições de ensino superior (Arruda, 2001b, pp. 37 e 212).
Ressalta-se que a noção de “ideologia de Estado", formulada neste texto como chave interpretativa das ideias políticas do período, estava em desacordo com a perspectiva de Wanderley Guilherme dos Santos a respeito das motivaçóes que teriam movido a escrita do pensamento político:

Desde a Independência que o problema teórico e prático predominante e de alta visibilidade das elites políticas e intelectuais brasileiras tem sido fundamentalmente este: de que modo implantar e garantir eficiente funcionamento da ordem liberal burguesa (1978, p. 50).

Embora a discordância tenha sido explicitada por ambos em seus respectivos textos, o que pretendemos enfatizar aqui é o ponto para o qual convergem, qual seja, o da valorização do pensamento político-social da Primeira República. Ao destacar o referido conjunto de autores, o elogio estendia-se à "forma narrativa" do "ensaio histórico", que foi uma das principais marcas do estilo intelectual das gerações da primeira metade do século XX (Lamounier, 1982, p. 411). Assim, no mesmo passo em que uma cultura cientificista era acionada, exaltava-se justamente a chamada tradição ensaística do pensamento político-social, representada por Florestan Fernandes, na década de 1950, como "pouco científica”. Observa-se, por conseguinte, que o princípio classificatório ligado à oposição entre ensaio e ciência adquire sentidos conflitantes no âmbito das disputas entre o grupo paulista e o mineiro/carioca.

A ideia de continuidade que Wanderley Guilherme dos Santos pretendia construir em relação aos ensaios do início do século exigia a montagem de uma lógica atinente à divisão da história do pensamento social em períodos. Sua perspectiva sustentava-se numa crítica à versão concorrente, que assinala o marco institucional como inflexão decisiva, no que se refere ao advento da fase propriamente "disciplinar" dos estudos sociais ${ }^{12}$. A consequência principal dessa periodização é, para Santos, a desvalorização de toda produção anterior ao surgimento do aparato universitário na década de 1930, como se a produção ensaística tivesse menos legitimidade em função da ausência de seu suporte institucional ${ }^{13}$.

De acordo com Santos, alguns fatores contribuíram para a difusão da versão da história do pensamento social brasileiro defendida por Florestan Fernandes. O período autoritário que vai de 1937 a 1945, a inexistência de uma tradição organizada de estudos históricos, bem como a influência no meio intelectual brasileiro de cientistas sociais estrangeiros, teriam pro- 
duzido uma "aparente descontinuidade" entre o pensamento político contemporâneo e do passado (Santos, 1978, p. 23). Tal percepção teria favorecido a difusão de esquemas interpretativos que, como o de Florestan Fernandes, tomavam os cânones universais que orientam o trabalho científico como o único critério seguro de avaliação sobre as virtudes do pensamento produzido.

Não por acaso, Bolívar Lamounier referenda inteiramente esta avaliação e acrescenta que o modelo analítico sustentado pelo sociólogo paulista ligado à matriz institucional - estaria irremediavelmente vinculado à visão que associa a "apreensão correta da 'realidade' à assimilação da parafernália acadêmica [...] e não ao conteúdo substantivo das interpretações” (Lamounier, 1985, p. 349).

Nesse sentido, o marco temporal estabelecido por Florestan Fernandes teria produzido uma cisão entre ensaio e ciência como se ambos correspondessem a momentos de um processo evolutivo, no qual a etapa institucional equivaleria a uma fase superior do desenvolvimento do saber. Uma vez que a arbitrariedade contida nesse raciocínio é exposta, a argumentação dos cientistas políticos sugere que o marco temporal seja relativizado. No âmbito desse questionamento, Wanderley Guilherme dos Santos pontifica:

A simplicidade da perspectiva permite que a crítica se exima de ser complexa. Com efeito, a historiografia que ordena o passado em função do presente, e assumindo o presente como o "moderno", está desarmada para entender as exatas articulaçôes do desenvolvimento intelectual da humanidade (Santos, 1967, p. 186).

Parece possível afirmar que a lógica descrita poderia ser mobilizada para questionar a perspectiva do próprio autor, já que o destaque dado à "inflexão" provocada pelos ensaios de 1920 e de 1930 tampouco deixa de se constituir a partir de um ângulo situado em meio às disputas vividas no presente. Isto nos leva a crer que ambos os pontos de vista, de Santos e de Fernandes, estão fundados num recurso similar que são as representaçôes sobre a própria origem, postas a serviço dos interesses em jogo no momento em que o discurso se enuncia. Embora divergentes, as perspectivas assemelham-se quanto ao sentido estratégico que tais representaçôes assumem na afirmação dos respectivos projetos acadêmicos. Nesse sentido, as periodizações são mais bem compreendidas quando situadas no âmbito das lutas entre os agentes em torno das classificações das fases que dividem, ou não, a história do pensamento. 
14.A obra Ospartidose as eleiçôes no Brasil, de 1975, co-organizada por Bolívar Lamounier e Fernando Henrique Cardoso (1978), pode ser mencionada como um bom exemplo da produção ligada ao referido contexto. Resultado de pesquisas desenvolvidas no âmbito do Centro Brasileiro de Análise e Planejamento (Cebrap), o livro teve considerável repercussão pública no momento em que foi lançado.
É interessante notar que ambas as versões redundariam em dois programas de pesquisa sobre história intelectual baseados em ênfases analíticas diversas: de um lado, a precedência das ideias e, de outro, o acento dado às instituiçôes. No Rio de Janeiro, o grupo reunido em torno do Centro de Pesquisas e Documentação de História Contemporânea do Brasil (CPDOC), criado em 1973, consolida a perspectiva da história das ideias que seria marcada justamente pela valorização da produção ensaística da primeira metade do século, sobretudo por meio do recurso à análise interna dos textos. Em São Paulo, o paradigma da "institucionalização" seria atualizado pelo projeto "História das Ciências Sociais no Brasil", levado a cabo no Instituto de Estudos Econômicos, Sociais e Políticos (Idesp), fundado em 1980. No caso paulista, a visão institucional seria o suporte da prática de uma sociologia dos intelectuais que procura enfatizar as ligações entre o texto e as condições ligadas à sua produção.

A lógica que rege as opções teórico-metodológicas parece se tornar mais clara quando a situamos no âmbito das disputas intelectuais que reverberam no manejo da pesquisa historiográfica. Seguindo a trilha desse raciocínio, é possível reconhecer a parcialidade dos dois pontos de vista, cujos diagnósticos favorecem mais ou menos ao estatuto de cada cidade no que se refere à sua importância relativa ao processo de constituição tanto do "pensamento social" como das "ciências sociais" no Brasil. Nesse sentido, o exame sobre as disputas regionais que foram destacadas acima parece contribuir para a tarefa de elucidação dos fatores que incidiram sobre a afirmação do novo perfil disciplinar da ciência política. De certo modo, as iniciativas do grupo ora examinado enquadram-se numa reação mais difusa ao que era visto como uma hegemonia paulista no cenário brasileiro das ciências sociais até a década de 1960.

No entanto, o elogio feito pelos cientistas políticos a certos autores do passado segue uma lógica própria que se explica em função do contexto político e intelectual de fins da década de 1970. O entusiasmo criado em torno das eleições de 1974, a partir dos resultados amplamente favoráveis à única legenda de oposição ao regime militar - o Movimento Democrático Brasileiro (MDB) -, daria ensejo a uma aposta no caminho eleitoral como condutor da transição do regime militar em direção à democracia ${ }^{14}$. A efervescência política criada em torno desse evento teve um rebatimento imediato no âmbito das pesquisas acadêmicas já devidamente reforçadas com o aparato metodológico adquirido nos Estados Unidos.

A ênfase no sistema representativo, além de revelar a perspectiva teórica subjacente a essa área de estudos, explicitava o caráter normativo de certa 
visão sobre a política. Trata-se do aporte doutrinário trazido das viagens de treinamento acadêmico, que forneceram a gama de valores sobre os quais repousam as pesquisas sobre a democratização. Assim, a obsessão pelos mecanismos formais do arranjo democrático explica-se em função da correspondência valorativa que se estabelecia entre "estabilidade" e "institucionalização política". Foi justamente no registro da "fragilidade" das instituições de representação que os problemas políticos do país foram formulados, o que se constituiria como fator explicativo predominante acerca dos acidentes da vida pública brasileira.

A construção da linhagem intelectual respondia à demanda ligada aos problemas práticos com os quais a disciplina se encontrava às voltas naquele contexto. O elogio aos autores do pensamento político-social era feito em função do lastro que poderiam fornecer ao argumento a um só tempo político e teórico em favor do processo de reforma institucional. Nesse sentido, as referências brasileiras que eram selecionadas dialogavam com o problema do "desenvolvimento político", cuja matriz era sugerida por teóricos norteamericanos, tais como Samuel Huntington e Juan Linz - cientista político espanhol radicado nos Estados Unidos.

A problemática da "institucionalização" formulava-se a partir da convergência de dois domínios que constituiriam os eixos principais de reflexão da nova geração de cientistas políticos: a formação do Estado nacional e a consolidação dos mecanismos formais de representação.

O primeiro deles ilustra a amplitude do escopo das investigações desenvolvidas pelo grupo geracional e explicita o nexo que se pretendia estabelecer entre a temática eleitoral e o debate mais abrangente acerca da formação histórica do país. Nesse sentido, a importância concedida ao pensamento autoritário explica-se em função da ideia que se criava em torno do processo de "desenvolvimento político", cujo ponto de partida remeteria justamente à consolidação do poder público central ${ }^{15}$. É nesse registro que a agenda temática dos ensaios do início do século - ligada à questão do Estado - é tomada pelo que seria o significado inaugural de uma "tradição" de estudos políticos. Construía-se, assim, o engate da especialidade institucional no seio de problemas intelectuais mais amplos que implicavam interpretações abrangentes sobre a história brasileira ${ }^{16}$.

Foi no âmbito do segundo domínio de reflexões que o elogio feito por Bolívar Lamounier a Vítor Nunes Leal adquiriu sentido. Além da exaltação das virtudes metodológicas presentes em Coronelismo, enxada e voto, de 1948, Lamounier enxerga nesta obra as bases para a construção de uma
15.Em artigo de 1974 , Fábio Wanderley Reis descreve as fases do desenvolvimento político, entre as quais a primeira diria respeito ao processo de formação e consolidação do Estado, que teria sido o núcleo da agenda político-intelectual até 1930 (Reis, 1974).

16. O eixo temático referente à formação do Estado redundou na escrita de parte das teses acadêmicas produzidas nos Estados Unidos. Eis alguns exemplos de trabalhos publicados em português: o livro de Simon Schwartzman, São Paulo e o Estado Nacional(1975), e o de José Murilo de Carvalho, $A$ construção da ordem (1980). 
perspectiva mais otimista quanto ao processo de desenvolvimento político no Brasil. A análise de Nunes Leal é destacada sobretudo porque permite sustentar que as instituições liberal-democráticas são viáveis no Brasil, apesar do histórico de clientelismo que marca a formação social brasileira. Segundo Lamounier, a obra de 1948 teria produzido um deslocamento interpretativo em relação à visão que assinala a incompatibilidade entre as ideias liberais e a realidade social do país. Nesse sentido, pretendia afirmar a importância do diagnóstico formulado no livro segundo o qual o arcabouço de instituiçóes políticas que se criava a partir de 1930, ainda que incipiente, representaria tanto um decréscimo do poder privado no Brasil como um reforço dos mecanismos de regulação social.

É no contexto dessa discussão que Bolívar Lamounier propõe uma espécie de revisão das versões sobre a história do Brasil que teriam produzido um "circuito fechado":

Formou-se entre nós um discurso que aprisiona o problema da representação no rígido e pobre contraste entre o Brasil legal e o Brasil real: entre as "elites" e as "massas"; entre a cidadania abstrata e o voto de cabresto; entre a lei eleitoral e sua fraude (Lamounier, 1981, p. 237)

Crítico do paradigma historiográfico das “ideias fora do lugar”, o cientista social afirma taxativamente a importância dos mecanismos representativos, assinalando a viabilidade de sua consolidação a despeito dos antecedentes desfavoráveis ligados à herança colonial. $\mathrm{O}$ argumento de Lamounier apostava na noção de autonomia da esfera política, em que as engrenagens democráticas constituiriam um sistema diferenciado mantendo-se relativamente imune aos determinantes advindos da estrutura social.

No seu esforço de libertar os horizontes da nação do que seriam as avaliações pessimistas inspiradas no marxismo, o cientista político interpreta o período republicano no Brasil sob outra chave analítica, concebida como antídoto aos diagnósticos de uma "historiografia convencional", segundo seus próprios termos (Lamounier, 2005, pp. 18-19). É possível dizer que sua revisão historiográfica foi concebida em função de um enfrentamento ideológico, em que seu ideário liberal de democracia exigia uma versão menos pessimista sobre a história política do que aquelas difundidas pelo Partido Comunista (PC), em geral, denunciador das "mazelas" ligadas ao latifúndio.

É nesse sentido que Vitor Nunes Leal desempenhou um papel central na construção das filiações, já que se tratava de um dos primeiros esforços 
de "livrar-se do velho chavão segundo o qual as instituições representativas constituíam mera fachada" (Lamounier, 1982, p. 414). O elogio a Gláucio Ary Dillon Soares seguiu lógica similar, uma vez que seu livro ${ }^{17}$, um dos precursores das análises sobre a experiência democrática de 1946 a 1964 , mostrou que tal período teria significado, "bem ou mal", um incremento de cidadania, de participação política e das bases ideológicas do sistema partidário (p. 416).

Apesar de críticos das perspectivas mais assumidamente doutrinárias que marcaram os intelectuais do Iseb e o marxismo que se difundia no meio intelectual brasileiro, os estandartes da cultura cientificista que era introduzida em fins dos anos de 1960 não se furtaram a emitir proposições normativas sobre o processo de "modernização" do país. Assim, a geração de especialistas ligava-se a um gênero de atuação política compatível com a linguagem científica que era acionada: a da intervenção técnica.

Ressalte-se, por fim, que o processo de construção da ciência política como disciplina autônoma está situado em um contexto mais abrangente ligado a transformaçôes que alteraram o perfil organizacional da prática acadêmica no Brasil. O estilo de trabalho introduzido pelos cientistas políticos relacionava-se com as iniciativas de difusão de um novo ideal de profissionalismo que foi moldado a partir da confluência entre dois fatores: os influxos da Fundação Ford e a criação de um sistema nacional de pós-graduação, previsto pela reforma universitária, de 1968, como parte do projeto concebido pelo regime militar de "modernização" do sistema universitário e científico.

Escoradas numa espécie de elogio à profissionalização, as "novas disciplinas" - a ciência política e a antropologia - fincariam sua presença no sistema acadêmico brasileiro, equilibrando o jogo de forças que até então era amplamente favorável à sociologia. Trata-se de um momento de transição geracional intrínseco à estrutura dos processos de desenvolvimento das ciências sociais, em que as clivagens entre geraçôes respondem a desacordos que apontam para sentidos conflitantes acerca do grau de especialização e de engajamento público do intelectual.
17.Ver Soares (1973). 


\section{Referências Bibliográficas}

Arruda, Maria Arminda do Nascimento. (2001a), "A modernidade possível: cientistas e ciências sociais em Minas Gerais". In: Miceli, Sergio (org.). História das ciências sociais no Brasil. São Paulo, Sumaré, vol. 1.

. (2001b), Metrópole e cultura: São Paulo no meio século XX. Bauru, SP, Educ.

CANEdo, Letícia. (2004), "Heranças e aprendizagens na transmissão da ordem política brasileira". Cadernos Ceru, 15.

. (2003), "A produção genealógica e os modos de transmissão de um capital político em Minas Gerais”. Brasil Genealógico, 3 (4).

. (2009), "Les boursiers de la Fondation Ford et la recomposition des sciences sociales brésiliennes: le cas de la science politique". Cahiers de la Recherche sur l'Éducation et les Saviors, 2.

Cardoso, Fernando Henrique \& Lamounier, Bolívar (orgs.). (1978), Os partidos e as eleiçôes no Brasil. São Paulo, Cebrap/Paz e Terra.

. (1978), "A bibliografia sobre ciência política no Brasil (1949-1974)". Dados, 18: 3-32.

Carvalho, José Murilo. (1996), A construção da ordem. 2 ed. Rio de Janeiro, Relume Dumará.

Dezalay, Yves \& Garth, Bryant. (2002), The internationalization of palace wars: lawyers, economists, and the contest to transform Latin American States. Chicago, The University of Chicago Press.

FERnANDes, Florestan. (1977), A sociologia no Brasil: contribuição para o estudo de sua formação e desenvolvimento. Petrópolis, Vozes.

ForJAz, Maria Cecília Spina.(1997), "A emergência da ciência política no Brasil: aspectos institucionais". Revista Brasileira de Ciências Sociais, 35, nov.

LAMOUnier, Bolívar. (1977), "Formação de um pensamento político autoritário na Primeira República: uma interpretação". In: FAusto, Boris. História geral da civilização brasileira. O Brasil republicano. São Paulo, Difel, vol. 9.

. (1981), "Representação política: a importância de certos formalismos". In:

Lamounier, B.; Benevides, Maria Victória e Weffort, Francisco (orgs.), Direito, cidadania e participação. São Paulo, T. A. Queiroz.

. (1982), "A ciência política no Brasil: roteiro para um balanço crítico". In: (org.). Ciência politica nos anos 80. Brasília, UnB.

(1999), "Vitor Nunes Leal: coronelismo, enxada e voto". In: MотA, Lourenço Dantas (org.), Introdução ao Brasil: um banquete no trópico. São Paulo, Senac. . (2005), Da independência a Lula: dois séculos de política brasileira. São Paulo, Augurium. 
Limongi, Fernando (2001a), "Institucionalização política”. In: Miceli, Sergio (org.). O que ler na ciência social brasileira (1970-1995). Ciência Política. São Paulo, Sumaré.

. (2001b), "Mentores e clientelas da Universidade de São Paulo". In: Miceli, Sergio (org.), História das ciências sociais no Brasil. 2 ed. São Paulo, Sumaré, vol. 1. Miceli, Sergio. A desilusão americana: relaçôes acadêmicas entre Brasil e Estados Unidos. São Paulo, Sumaré.

. (1993), "A aposta numa comunidade científica emergente: a Fundação Ford e os cientistas sociais no Brasil 1962-1992”. In: (org.), A Fundação Ford no Brasil. São Paulo, Sumaré.

. (2001), "Por uma sociologia das ciências sociais". In: (org.), História das ciências sociais no Brasil. 2 ed. São Paulo, Sumaré.

Oliveira, Lúcia Lippi. (1999), "Interpretações sobre o Brasil”. In: Miceli, Sergio. O que ler na ciência social brasileira (1970-1995). Sociologia. São Paulo, Sumaré, vol. 2.

Miceli, Sergio; Ferreira, Marieta de Moraes \& Castro, Celso. (1998), "Entrevista com José Murilo de Carvalho". Estudos Históricos, 1998, vol. 12.

ReIs, Elisa Pereira. (1993), "A construção intelectual e a política das ciências sociais brasileiras: a experiência do Iuperj”. In: Micelı, Sergio (org.). A Fundação Ford no Brasil, São Paulo, Sumaré.

ReIs, Fábio Wanderley. (1996), “A propósito de ciência e dialética”. Revista Brasileira de Ciências Sociais, 1 (4): 299-309, Belo Horizonte, UFMG.

. (1974), "Solidariedade, interesses e desenvolvimento político". Cadernos DCP, Belo Horizonte, pp. 5-58.

SANTOS, Wanderley Guilherme dos. (1963), Introdução ao estudo das contradiçôes sociais no Brasil. Rio de Janeiro, Iseb.

. (1967), "A imaginação político-social brasileira". Dados, 3: 133-149.

. (1970), "Raízes da imaginação política brasileira”. Dados, 7: 137-161.

. (1978) "Paradigma e história: a ordem burguesa na imaginação social brasileira”. In: Ordem burguesa e liberalismo político. São Paulo, Duas Cidades. - (1980), "A ciência política na América Latina". Dados, 1 (23): 15-27.

Schwartzman, Simon. (1975), São Paulo e o estado nacional. São Paulo, Difel.

SoAres, Gláucio Ary Dillon. (1974), Sociedade e política no Brasil. São Paulo, Difel. Toledo, Caio Navarro de. (1997), Iseb: fábrica de ideologias. Campinas, Editora da Unicamp. 


\section{Resumo}

\section{A gênese da ciência política brasileira}

$\mathrm{O}$ artigo analisa dimensões constitutivas da afirmação, a partir de fins dos anos de 1960, da ciência política no Brasil. Amparada pelo auxílio da Fundação Ford e impulsionada pela iniciativa de um grupo geracional, essa disciplina acadêmica tem sua legitimidade ancorada na reivindicação de uma cultura científica que, em alguns casos, lastrearia a intervenção técnica na transição democrática. Proclamando a ruptura com o padrão de trabalho vigente nas ciências sociais brasileiras, este grupo, entretanto, estabelece continuidades com a tradição nacional de pensamento político-social. A desqualificação de grupos acadêmicos rivais e a evocação do aporte simbólico de uma tradição são duas facetas de um mesmo processo de autonomização disciplinar.

Palavras-chave: Ciência política; Grupo geracional; Inovação científica; Fundação Ford; Pensamento político-social.

\section{Abstract}

The genesis of Brazilian political science

The article analyzes the constitutive dimensions of the affirmation of political science in Brazil, which began in the late 60s. With the support of the Ford Foundation and driven by the initiative of a generational group, the legitimacy of this academic discipline is anchored in demands for a scientific culture that would, in some cases, buoy technical intervention during the democratic transition. Announcing their rupture from the prevailing standard of work in the Brazilian social sciences, this group nonetheless established continuities with the national tradition in politico-social thought. The disqualification of rival academic groups and the evocation of the symbolic sup-

Texto recebido em $1 / 2 /$ 2010 e aprovado em $24 / 2 / 2010$.

Fábio Cardoso Keinert é mestre e doutorando em sociologia pela Universidade de São Paulo - USP. E-mail: fabiock@usp.br.

Dimitri Pinheiroémestre em sociologia pela Universidade de São Paulo - USP. E-mail: dimitri.silva@usp.br. port of a tradition are two facets of the same process of disciplinary independence.

Keywords: Political science; Generational group; Scientific innovation; Ford Foundation; Politico-social thought. 